Using a derivation similar to Porter's, but allowing for shear stresses, we can obtain

$$
\int_{p_{k_{1}}}^{p_{k_{\mathrm{z}}}} s_{k} d p_{k}+\int_{p_{n_{1}}}^{p_{n_{\mathrm{s}}}} s_{n} d p_{n}=\int_{h_{1}}^{h_{\mathrm{z}}} v d h
$$

Here $p_{k_{0}}$ and $p_{n_{0}}$ are the hydrostatic and shear components of the directional stresses applied to raise the vapour pressure of the gel to $h_{0}$ without change in moisture content, $s_{k}$ is Porter's $s$ involving only volume change and $s_{n}$ is $V$ times the change in shear strain per unit change in moisture content.

If the shear components contained in the second integral are elastic, the work done on the gel during adsorption is recoverable on desorption and this process is reversible. If they are plastic, the work done in shear will not be recoverable and an equal work must be done again on desorption, so that the second integral in equation (2) will not change sign.

Once the plastic shear stresses have disappeared $p_{k_{0}}$ will become equal to Porter's $p$, so the first integral is independent of plastic shear components. The second integral is always positive so it is evident that $\int v d h$ must be greater on adsorption than on desorption, which is possible if, at any moisture content, the adsorption vapour pressure be greater than the desorption, except at the upper and lower limits of the integrated cycle.

This appears to be a valid explanation of the hysteresis in gels. If the gel is only partially plastic, hysteresis will still occur, but to a smaller extent, so the narrowing of the hysteresis loop at lower vapour pressures is thus explicable in terms of the increasingly elastic behaviour of gels as they become drier.

Some explanations of hysteresis which have been suggested, for example by Zsigmondy ${ }^{3}$ or McBain ${ }^{4}$, can only be valid for liquid held by capillary forces and cannot account for hysteresis in liquid held by purely molecular sorption on the surfaces of the micelles but, in wood at any rate, there is also evidence of hysteresis in molecular sorption ${ }^{5}$. Urquhart ${ }^{6}$ postulates that the swelling of the gel opens up fresh intermicellar surfaces to the sorption, and this is probably true, but it is difficult to see why this effect should not be reversible if sufficient time is given for equilibrium to be established on desorption, unless the deformation is plastic.

The points in favour of the theory of hysteresis here presented are (1) that it depends only on considerations of energy, and (2) that it is accounted for in terms of those elastic properties which distinguish gels from solutions.

The work done in shear will depend on restraints imposed on the gel during moisture changes and will not be a property of the gel itself. The restraints may, however, be inherent in the form in which the gel usually occurs, so evidence is required to show that shear stresses are likely to occur during actual drying or wetting. In wood we have a material which provides definite evidence of shear stresses arising, during natural shrinkage, from the ordered change in shape of the cell structure. During drying, the shrinkage (change in volume per unit volume) of the external dimensions of the hollow cell is considerably less than that of the cell wall material, owing to the restraint imposed by the thin outer sheath (the primary wall) in which the cell is encased, and the area of the void centre therefore becomes a larger proportion of the total cross section. This introduces a shear strain in the cell wall which may be approximately determined.
The gel material of other natural fibres is likely to have similar restraints imposed on it during shrinkage. In amorphous gels also, it is probable that shear stresses are introduced because they consist of a network of micelles and it seems unlikely that, by removing water, a reduction in the external dimensions of such a network would be possible without distorting the interlocking meshes. The micelles possess rigidity so some work will be done during this distortion and, if they are partially plastic, the hysteresis must result.

W. W. Barkas.

Forest Products Research Laboratory, Princes Risborough, Aylesbury, Bucks. Oct. 31 .

${ }^{1}$ Katz, Kolloidchem. Beihefte, 9 (1917).

Porter, Proc. Roy, Soc., A, 79, 519 (1907).

3 Zsigmondy, A., Anorg. Chem., 20, 157 (1909).

¿MeBain, J. Amer. Chem. Soc., 5\%, 699 (1935).

5 Barkas, Trans. Farad. Soc., 36, 824 (1940).

- Urquhart, Shirley Inst. Mem., 8, 19 (1929).

\section{The Sligo Artefacts}

WHEN, in $1927^{1}$, I announced the discovery of the Sligo artefacts, it was asserted, by certain observers, that these specimens were not of human origin, but had been flaked by wave-action which, at times, is very powerful on the west coast of Ireland.

During 1941, fourteen years after my discovery was made, I again visited Sligo, and found that no further specimens, such as I had collected originally, were visible upon the site. Indeed it was obvious that no fracturing by wave-action. of the limestone rocks there had taken place since 1927 ; though, if such fracturing were a reality, the conditions present appeared to be admirably suitable for its successful operation.

The Sligo evidence thus disposes of the claim that wave-action is capable of fracturing hard limestone rock in a manner indistinguishable from intentional human flaking.

30 Southwick Street,

London, W.2. Oct. 24.

2 NATURE, 120, 260 (1927).

\section{Symbiosis of Men and Animals}

WHen Sturt discovered the Darling River he left the following notes, for which $\mathrm{I}$ am indebted to $\mathrm{Mr}$. Charles Daley, secretary of the Historical Society :

1. "The channel of the river was from 70 to 80 yards broad, and enclosed an unbroken sheet of water evidently very deep, and literally covered with pelicans and other wild fowl."

2. "Yet as I stood upon its bank at sunset, when not a breath of air existed to break the stillness of the water below me and saw the surface kept in constant agitation by the leaping of fish I doubted whether the river could supply itşelf so abundantly."

Where now are the pelicans and the fish? And we may echo, where are the vast numbers of seals that were in Bass Straits? And where are the fish which were also abundant? The fish scarcity is entirely man made, and if men act sensibly they can rectify much of the damage? It will be noted that though pelicans were abundant, so were the fish. There is a symbiosis both with regard to pelicans and fish, and seals and fish. The experience of the Priviloff Islands makes that perfectly clear.

103-105 Collins Street,

JAMES W. Barretr. 